Check for updates

Cite this: Mater. Adv., 2022, 3,2434

Received 1st September 2021 Accepted 12th January 2022

DOI: 10.1039/d1ma00793a

rsc.li/materials-advances

\title{
Enhancing the material performance of chloroprene rubber (CR) by strategic incorporation of zirconia $\dagger$
}

\author{
Shubham C. Ambilkar, ${ }^{a}$ Gopal Lal Dhakar, ${ }^{a}$ Bharat P. Kapgate, ${ }^{\text {b }}$ Amit Das,

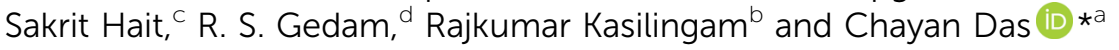

\begin{abstract}
Chloroprene rubber (CR) composites, embedded with well dispersed zirconia within the matrix, are produced that combine the superior reinforcement of zirconia with the other useful composite properties. The in situ incorporated zirconia offers an outstanding reinforcement effect in comparison to externally filled zirconia at the same filler content. The modulus at $100 \%$ strain becomes four times higher for a $20 \mathrm{phr}$ in situ filled zirconia composite, with respect to an unfilled compound while the tensile strength becomes three times higher. A notable improvement in thermal stability is exhibited by an increase in the onset temperature and maximum degradation temperature by ca. $30{ }^{\circ} \mathrm{C}$ and $20^{\circ} \mathrm{C}$ respectively upon in situ zirconia incorporation. The use of two selected organosilanes results in further improvement in composite properties. A study on the dielectric properties of the composites seems very encouraging. The zirconia filled composites also respond very well to a series of testing viz. resistance to oil, aging and abrasion exhibiting their suitability for practical application.
\end{abstract}

\section{Introduction}

Metal oxide based non-black fillers have emerged as potential candidates for the reinforcement of elastomeric materials in the past few decades. ${ }^{1}$ Other than the reinforcement effect, they could add many useful properties such as dielectric, antimicrobial, and optical properties to the composites that cannot be otherwise achieved using traditional carbon black fillers. ${ }^{2-5}$ Furthermore, non-black fillers are free from environmental hazards associated with carbon black. For example, carbon black is derived from non-renewable petroleum sources and is carcinogenic in nature. Moreover, carbon black produces greenhouse gases on burning that impart a negative effect on the carbon footprint. ${ }^{6}$ In the category of metal oxide based non-black fillers, silica became the most popular one. ${ }^{7-14}$ It has proven its potential towards rubber reinforcement along with offering a balance between improved rolling resistance and anti-skid properties. Titania followed next to offer several useful features in addition to significant reinforcing efficiency.

\footnotetext{
${ }^{a}$ Department of Chemistry, Visvesvaraya National Institute of Technology, Nagpur, India. E-mail: chayandas@hotmail.com

${ }^{b}$ Indian Rubber Materials Research Institute, Thane, India

${ }^{c}$ Leibniz-Institut für polymerforschung, Dresden e.V, Germany

${ }^{d}$ Department of Physics, Visvesvaraya National Institute of Technology, Nagpur, India

$\dagger$ Electronic supplementary information (ESI) available. See DOI: 10.1039/ d1ma00793a
}

Research studies on titania-based elastomers are being taken up by the scientific community, working in this area, with great interest. ${ }^{415-18}$ However, the role of zirconia in developing elastomeric composites has remained underexplored to date. Zirconia is a ceramic material that is well recognised for its striking mechanical strength, very high thermal stability and biocompatibility. ${ }^{19}$ Accordingly, it became a very good choice for a number of applications. There are plenty of reports where zirconia has been utilised to enrich the properties of polymer composites for a variety of polymers such as polymethyl methacrylate (PMMA), ${ }^{20}$ epoxy resin, ${ }^{21}$ polyindole, $^{22}$ polyamide $^{23}$ polydimethylsiloxyl (PDMS) ${ }^{24}$ and polyaniline. ${ }^{25}$ Those studies were focussed on the diverse aspects of zirconia based polymer composites that cover mechanical, thermal, optical, dielectric, antimicrobial and other important properties. However, the potential of zirconia has not been extended towards rubber-like materials considerably. There are a handful of reports on zirconia containing elastomeric composites. Mahammad et $a .^{26}$ reported epoxidized natural rubber/zirconia hybrid films that exhibited excellent optical transparency and improved thermal stability. This group also reported good hardness and excellent electrical conductivity for zirconia filled composites. ${ }^{27}$ Yang et al. ${ }^{28}$ prepared silicone rubber composites containing $\mathrm{ZrO}_{2}$ to investigate the improvement in mechanical properties, thermal stabilities and ablation behaviour. Wen et $a .^{29}$ synthesized PMMA composites comprising a zirconia containing mixed oxide network. A very good mechanical 
performance was demonstrated by the polymer matrices owing to the narrow distribution size of the filler. Murugesen et al. ${ }^{30}$ synthesized in situ filled titania-zirconia-PDMS composites that demonstrated very good stress-strain properties. Parera et al. ${ }^{31}$ incorporated in situ zirconia in natural rubber to improve the hardness and abrasion resistance of the composites. Amrishraj et $a .^{32}$ studied the mechanical, thermoelastic and thermal properties of acrylonitrile butadiene styrene composites filled with PTFE (poly tetrafluoroethylene) and nano-zirconia. Addition of zirconia was found to improve the mechanical properties, thermal stability and viscous behaviour of composites in this work.

A literature search on zirconia filled elastomer composites reveals a few reports that focus mostly on the optical properties. However, reinforcing the efficiency of zirconia towards elastomers has not been taken care of on a serious note. This tempted us to unfold the potential of zirconia, as a non-black filler, for the preparation of useful rubber materials. Chloroprene rubber (CR) is selected for this purpose, in the present work, since its polar nature allows it to better mix with zirconia. Otherwise, compatibility between an organic rubber and inorganic metal oxides remains an issue, in general. Chloroprene (CR) is a specialpurpose rubber, widely used in various commercial sectors including automobiles, construction, and textiles to name a few. ${ }^{33}$ Its beneficial features such as oil resistance, toughness, dynamic flex life, and adhesive capability make CR suitable for such diverse application. Besides this, the dielectric and electrical conductivity properties of CR composites make them useful in the fields of electromagnetic interference (EMI) shielding, microwave absorption, and conductive adhesives. The development of high-frequency electronic equipment demands good dielectric properties in combination with adequate mechanical strength and ease of processing which is a challenging task to acquire in a one-component material. CR can be a very good choice to develop such materials that combine the matrix's outstanding mechanical properties, thermal stability, and processability with the electrical properties. Nevertheless, selection of an appropriate filler, its concentration and state of dispersion remain very crucial in controlling the ultimate properties of the composites. ${ }^{34-37}$ Very recently, we reported zirconia filled nitrile rubber composites that exhibited superior mechanical properties of the composites. ${ }^{38}$ The present work is moving one step forward in establishing the merits of zirconia in developing practically useful CR composites. An in-depth investigation of the synthesised CR-zirconia composites has been performed, in a comparative manner, in terms of mechanical, thermal, rheological and viscoelastic properties. A study on the dielectric properties of the composites appears very encouraging. What's more, all the zirconia filled composites have been subjected to a series of testing, as per ASTM norms, to assess their material performances.

\section{Experimental}

\subsection{Materials}

Chloroprene rubber (LANXESS Bayprene 116, XD grade) was procured from Heritage Rubber (Nagpur, India). Zirconium(Iv) propoxide solution (70\% in 1-propanol) was bought from Sigma Aldrich (India). Zirconium dioxide (97\%) was purchased from Loba Chemie (India). Bis-(3-triethoxysilylpropyl) tetrasulfide (TESPT) and (3-aminopropyl) trimethoxysilane (APTES) were purchased from Evonik Degussa (Thailand). Tetrahydrofuran (THF) and toluene were purchased from Fisher Scientific Ltd (India).

\subsection{In situ synthesis of zirconia in CR by the solution sol- gel method}

A solution sol-gel process has been adopted, in this study, to generate well dispersed zirconia in situ in the chloroprene rubber (CR) matrix. This is schematically presented in Scheme 1. Zirconia particles are allowed to grow directly in the CR matrix from its precursor, zirconium(Iv) propoxide solution, under optimised reaction conditions. In this work, a polar solvent, tetrahydrofuran (THF), is used owing to its miscibility with water that is needed for hydrolysis. The reaction is performed at ambient temperature and the use of a catalyst does not seem necessary since percentage conversion of alkoxide to metal oxide is appreciable as such.

$25 \mathrm{~g}$ of small pieces of CR were dissolved in $400 \mathrm{ml}$ of tetrahydrofuran (THF) under stirring conditions. $18 \mathrm{ml}$ of zirconium(Iv) propoxide solution was added into the homogeneous rubber solution for the preparation of the composite, In-Zr-20. This is followed by the addition of water (mole ratio of zirconium(Iv) propoxide and water $=1: 2$ ) with stirring being continued for $60 \mathrm{~min}$. Then stirring was stopped and gelation was allowed to occur at ambient temperature for four days. Finally, the gel was dried at $80{ }^{\circ} \mathrm{C}$ under vacuum. For the preparation of In-Zr-20T and In-Zr-20A, the same procedure is followed except that TESPT and APTES $(1 \mathrm{~g}$ each, i.e., $0.93 \mathrm{ml}$ of

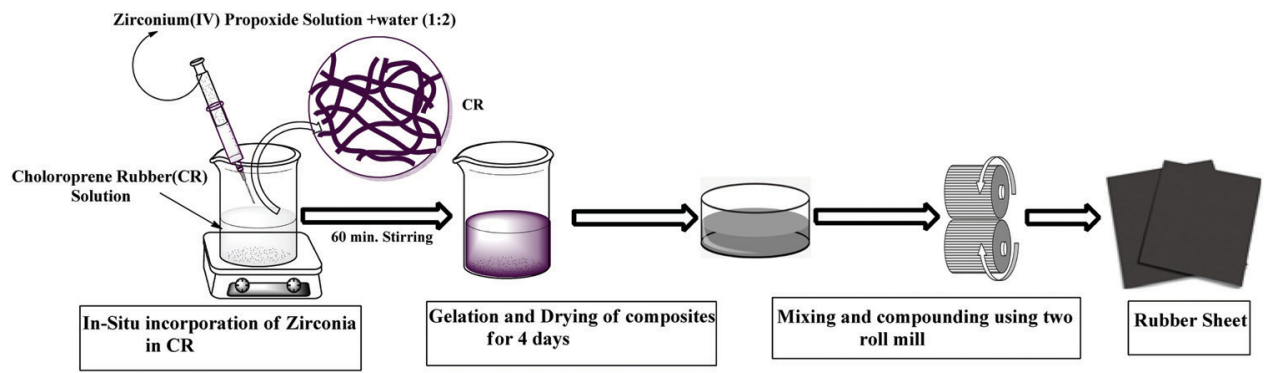

Scheme 1 Schematic representation of composite preparation. 
Table 1 Formulation for rubber compounds in phr (parts by weight per hundred parts of rubber)

\begin{tabular}{|c|c|c|c|c|c|c|}
\hline Sample code & Unfilled & In-Zr-20 & In-Zr-20T & In-Zr-20A & Ex-Zr-20 & Ex-Zr-20T \\
\hline In situ $\mathrm{ZrO}_{2}$ & 0 & 20 & 20 & 20 & & \\
\hline$\%$ of conversion & & 92.5 & 80.5 & 99 & & \\
\hline
\end{tabular}

Curing ingredients (in phr): ZnO: 5, stearic acid: 1, MgO: 4, ETU: 0.5, MBTS: 1, sulphur: 2 .

TESPT and $1.06 \mathrm{ml}$ of APTES) were added to the rubber solution, respectively, in addition to other ingredients.

\subsection{Formulation and compounding of rubber}

In situ zirconia filled rubber sheets were compounded on a two roll mill for $10 \mathrm{~min}$ with the addition of crosslinking ingredients given in Table 1. One unfilled sample was prepared for reference using the same procedure. Composite Ex-Zr-20 was prepared by mixing raw $\mathrm{CR}$, zirconium dioxide powder and other curing ingredients. For composite Ex-Zr-20T additionally TESPT was mixed. All the composites were subjected to compression molding at $160{ }^{\circ} \mathrm{C}$ for the duration of their respective cure time $\left(t_{90}\right)$.

\section{Characterization studies}

\subsection{Curing study}

The cure characteristics of the composites were assessed using a moving die rheometer, MDR Xgen100 (Future Foundation, India) at $160{ }^{\circ} \mathrm{C}$, for $60 \mathrm{~min}$ at a frequency of $1.66 \mathrm{~Hz}$. ISO 65022 standard was adopted for this measurement.

\subsection{Thermogravimetric analysis (TGA)}

The thermal analysis of the composites was done using a TG-DTA 7200 (Hitachi, Japan) in the temperature range of $40-800{ }^{\circ} \mathrm{C}$ (heating rate of $10{ }^{\circ} \mathrm{C} \mathrm{min}^{-1}$ ). The thermal scan was started under a nitrogen flow and changed to air at $600{ }^{\circ} \mathrm{C}$.

The zirconia content was calculated from eqn (1) to get the actual zirconia content in the filled composites; the ash content of unfilled sample/composite is subtracted from that of filled composites.

$$
\mathrm{ZrO}_{2} \text { content }(\mathrm{phr})=\frac{W}{100-W} \times 100
$$

where $W$ is the weight of the ash remaining (for all filled composites) after heating at $800{ }^{\circ} \mathrm{C}$.

(\%) Conversion of zirconium(Iv) propoxide to $\mathrm{ZrO}_{2}$ was calculated from eqn (2):

$$
\text { (\%) Conversion }=\frac{W}{W^{\prime}} \times 100
$$

where $W^{\prime}$ is the calculated amount of zirconia assuming a full conversion of zirconium(Iv) propoxide into zirconia.

The limiting oxygen index (LOI) is calculated using the Van Krevelen and Hoftyzer equation (eqn (3)): ${ }^{39}$

$$
\mathrm{LOI}=17.5+0.4 \mathrm{CR}
$$

where CR $=$ Char yield .

\subsection{Differential scanning calorimeter (DSC)}

The glass transition temperature $\left(T_{\mathrm{g}}\right)$ and change in specific heat capacity $\left(\Delta C_{\mathrm{p}}\right)$ of the selected samples were determined using a DSC 204 F1 (NETZSCH, Germany). In order to remove the volatile impurities, they are first heated up to $200{ }^{\circ} \mathrm{C}$ followed by quenching of the samples to $-50{ }^{\circ} \mathrm{C}$. Then a DSC scan was performed from $-50{ }^{\circ} \mathrm{C}$ to $30^{\circ} \mathrm{C}$ at a heating rate of $5{ }^{\circ} \mathrm{C}$ per min.

\subsection{Morphological study}

Scanning electron microscopy (SEM) images were recorded using an FESEM, MIRA3 TESCAN, USA, equipped with an energy-dispersive X-ray spectrometer (EDAX; Octane Prime, AMETEK, USA) at an acceleration voltage of 5 to $10 \mathrm{kV}$ with a working distance of $5 \mathrm{~mm}$. The size of particles was determined using Image J software.

\subsection{Mechanical characteristics}

Dumb-bell shaped specimens of vulcanized rubber sheets were subjected to stress-strain study using a Universal Testing Machine (UTM) (H 10 KT Tinus Olsen, UK). ISO 527 standard was followed using a load cell of $500 \mathrm{~N}$ with a crosshead speed of $200 \mathrm{~mm} \mathrm{~min}^{-1}$ at room temperature. Each composite was subjected to a stress-strain analysis thrice and the average value is tabulated. The analysis of variance (ANOVA) test was performed to do a standard error analysis of mechanical properties using Origin Pro 8 software.

\subsection{Swelling studies}

These studies show the degree of swelling and cross-linked density of the composites.

Degree of swelling $(Q)$ of the synthesised composites was determined by the following equation (eqn (4)):

$$
Q(\%)=\left(W_{\mathrm{s}}-W_{\mathrm{o}}\right) / W_{\mathrm{o}} \times 100
$$

where $W_{\mathrm{s}}$ is the weight of the sample after swelling and $W_{\mathrm{o}}$ is the weight of the sample before swelling.

Crosslinking densities $(\nu)$ were calculated using the FloryRehner equation $^{40}$ (eqn (5))

$$
v=-\left[\ln \left(1-V_{\mathrm{r}}\right)+V_{\mathrm{r}}+\chi V_{\mathrm{r}}^{2}\right] / V_{\mathrm{s}}\left(V_{\mathrm{r}}^{\frac{1}{3}}-V_{\mathrm{r}} / 2\right)
$$

where $V_{\mathrm{s}}$ is the molar volume of the toluene (106.2), $V_{\mathrm{r}}$ is the volume fraction of rubber in the swollen gel and $\chi$ is the Flory-Huggins interaction parameter which is 0.342 for the CR-toluene system. ${ }^{35}$ 


\subsection{Dynamic mechanical analysis (DMA)}

Dynamic mechanical analysis was performed with the help of an Eplexor $2000 \mathrm{~N}$ dynamic mechanical analyzer (Gabo Qualimeter, Ahlden, Germany) in the tension mode. The temperature range of measurement was $-100{ }^{\circ} \mathrm{C}$ to $+140{ }^{\circ} \mathrm{C}$ with a heating rate of $2{ }^{\circ} \mathrm{C} \mathrm{min}^{-1}$. Frequency was kept constant at $10 \mathrm{~Hz}$.

\subsection{Dielectric study}

Dielectric studies were carried out using a dielectric analyser (Alfa analyser, Novocontrol). All the measurements were done at ambient temperature over the frequency range of $10-10^{7} \mathrm{~Hz}$. The measurements were done on a disk shaped rubber sample with a thickness of $4 \mathrm{~mm}$ and a diameter of $13 \mathrm{~mm}$. The samples were placed between two silver plated electrodes of $20 \mathrm{~mm}$ diameter. In order to provide good contact between the samples and electrodes a silver paste was applied on the surface of the samples.

\subsection{Testing of oil, aging and abrasion resistance}

Oil resistance was evaluated according to the ASTM D471 standard. One square inch of the sample was cut and the initial volume was calculated from weight and specific gravity. The rubber specimen was then immersed into IRM 901 and IRM 903 oils for $70 \mathrm{~h}$ at $100{ }^{\circ} \mathrm{C}$. Then, the rubber samples were removed from the oil and cleaned with tissue paper. The final volume was calculated by determining the final weight. The swelling percentage of oil was calculated using the following formula (eqn (6)):

$$
\frac{\text { Initial volume }- \text { Final volume }}{\text { Initial volume }} \times 100
$$

Aging resistance study was performed according to ISO 37 standard. The dumb-bell shaped samples were kept in an air oven at $100{ }^{\circ} \mathrm{C}$ for $72 \mathrm{~h}$. After this, they were taken out and kept at room temperature for maturation for $16 \mathrm{~h}$. The tensile strength of the samples was determined and compared with that before aging. Each composite was subjected to a stressstrain analysis thrice and the average value is tabulated. The analysis of variance (ANOVA) test was performed to do a standard error analysis of the mechanical properties using Origin Pro 8 software.

For determination of abrasion resistance 1.5-2.0 $\mathrm{g}$ of the rubber sample was abraded on an abrasion drum at $84 \mathrm{rpm}$ and the distance covered was $40 \mathrm{~m}$ (as per IS3400 part 3); after this the abraded weight was taken and divided by specific gravity to obtain the volume loss.

\section{Results and discussion}

\subsection{Cure characteristics}

Cure characteristics of the composites are assessed by the rheological study and the results are summarized in Table 2. It is observed that the addition of zirconia increases the minimum torque $\left(M_{\mathrm{L}}\right)$ of the composites indicating immobilization of rubber chains due to occlusion of rubber within and between filler aggregates. ${ }^{41}$ Also, maximum torque, that depends on the stiffness and shear modulus of vulcanized samples, increases upon zirconia addition. This indicates an enhancement of the crosslinking degree in the rubber network. This observation corroborates the results obtained from the swelling study. The optimum cure time of the composites $\left(t_{90}\right)$ is reduced upon zirconia addition (Table 2). Optimum cure time is known to depend on the type of accelerator as well as on the ratio of accelerator to sulphur. It may be noted that MBTS, used in this work, is a semi-ultra-fast accelerator. Finally, with the addition of zirconia, the scorch time of the composites is found to increase.

\subsection{Thermogravimetric analysis (TGA)}

Thermogravimetric analysis reveals the three stage degradation of the composites in the temperature range of 100 to $800{ }^{\circ} \mathrm{C}$ (Fig. 1). The first decomposition above $250{ }^{\circ} \mathrm{C}$ is due to thermal decomposition of organic impurities. Next decomposition observed in the temperature range of $400-500{ }^{\circ} \mathrm{C}$ is due to the degradation of polymer chains. The last decomposition above $650{ }^{\circ} \mathrm{C}$ is attributed to the conversion of chars to $\mathrm{CO}_{2}$ when the flowing gas is switched from nitrogen to air. A significant improvement in thermal stability, brought by in situ zirconia, is evidenced from an appreciable increase in the onset temperature $\left(20-30{ }^{\circ} \mathrm{C}\right)$ for this group of the composites compared to that of unfilled CR gum. Notably, this is not so prominent for externally filled zirconia composites. This is consistent with the concurrent shift of $T_{\max }$ (temperature at which maximum weight loss occurs) to a higher temperature side as shown in Table 3. Credit for such an outstanding improvement in thermal stability goes to zirconia which is well known for its refractoriness. ${ }^{42}$ The well dispersed zirconia particles in the CR matrix are believed to serve as effective heat absorbers and act as a barrier against decomposition of the polymer chains that causes delay in the decomposition of the CR matrix. The highest improvement in thermal stability is shown by the APTES treated zirconia filled composite. It is believed that the $\mathrm{Cl}$ atoms present in the $\mathrm{CR}$ matrix are engaged in physical interaction with the amino group of APTES that

Table 2 Curing characteristics of unfilled and zirconia filled CR composites

\begin{tabular}{|c|c|c|c|c|c|c|}
\hline Sample code & Unfilled & In-Zr-20 & In-Zr-20T & In-Zr-20A & Ex-Zr-20 & Ex-Zr-20T \\
\hline Minimum torque (dNm) & 1.02 & 1.60 & 2.30 & 6.30 & 1.90 & 0.90 \\
\hline Maximum torque (dNm) & 2.70 & 3.90 & 4.90 & 14.20 & 12.50 & 6.90 \\
\hline$\Delta$ torque $(\mathrm{dNm})$ & 1.68 & 2.30 & 2.60 & 7.90 & 10.60 & 6.00 \\
\hline Cure time $\left(t_{90}\right)(\mathrm{min})$ & 18.03 & 22.15 & 35.1 & 40.09 & 31.33 & 34.48 \\
\hline Scorch time (min) & 2.32 & 10.12 & 8.25 & 9.9 & 2.39 & 2.49 \\
\hline
\end{tabular}




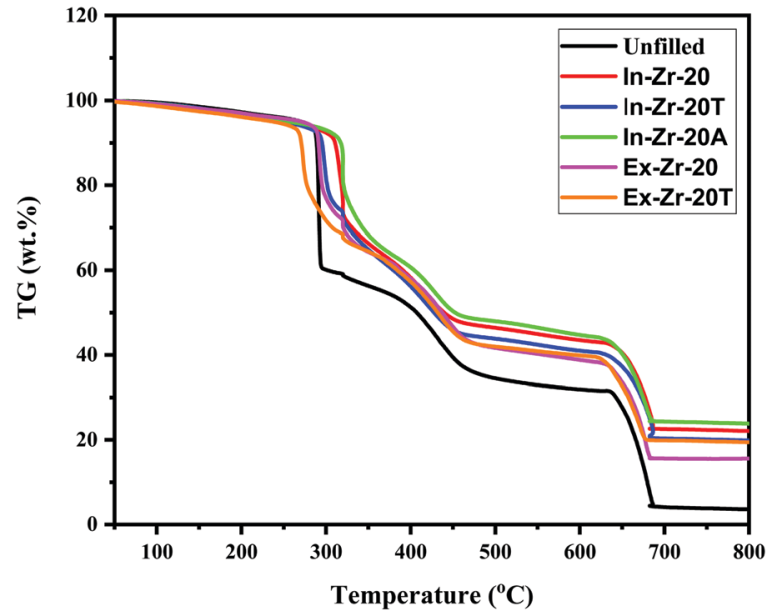

Fig. 1 Thermogram of unfilled and zirconia filled CR composites.

strengthens the rubber-filler interaction. This primarily contributes to the higher thermal stability of the APTES treated zirconia filled composite.

Flame retardancy of polymer composites is urgently required in many applications where nano-fillers could play a crucial role. The halogenated polymers like CR usually show flame resistance as they provide hydrogen halides which can serve as very good radical scavengers for ${ }^{\circ} \mathrm{H}$ and ${ }^{\circ} \mathrm{OH}$ radicals. ${ }^{36}$ We have theoretically studied the flame retardancy of the synthesised composites by calculating the char yield and LOI (limiting oxygen index) values ${ }^{43-45}$ (Table 3). The char yield of the filled composites increases from $32 \%$ (unfilled compound) to $37-45 \%$. At the same temperature, the LOI values (32-35) of the filled composites are also found to be appreciably higher than that (30) of unfilled compound. This definitely indicates improvement in flame retardancy of the CR composites brought by incorporation of zirconia and that is little better for in situ zirconia in comparison to externally filled zirconia.

\subsection{Differential scanning calorimetry (DSC)}

Determination of the glass transition temperature $\left(T_{\mathrm{g}}\right)$ of the selected samples by DSC reveals an increase of $T_{\mathrm{g}}$ by $\sim 3{ }^{\circ} \mathrm{C}$ for in situ filled composites relative to unfilled gum (Fig. 2 and Table 4). However, $T_{\mathrm{g}}$ of the externally zirconia filled composites is influenced marginally. The good rubber-filler interaction in filled composites restricts the mobility of the rubber chain that is reflected in the $T_{\mathrm{g}}$ value. The changes in the specific heat capacity $\left(\Delta C_{\mathrm{p}}\right)$ of the selected samples are also determined to have further insight into filler activity. In situ filled composites

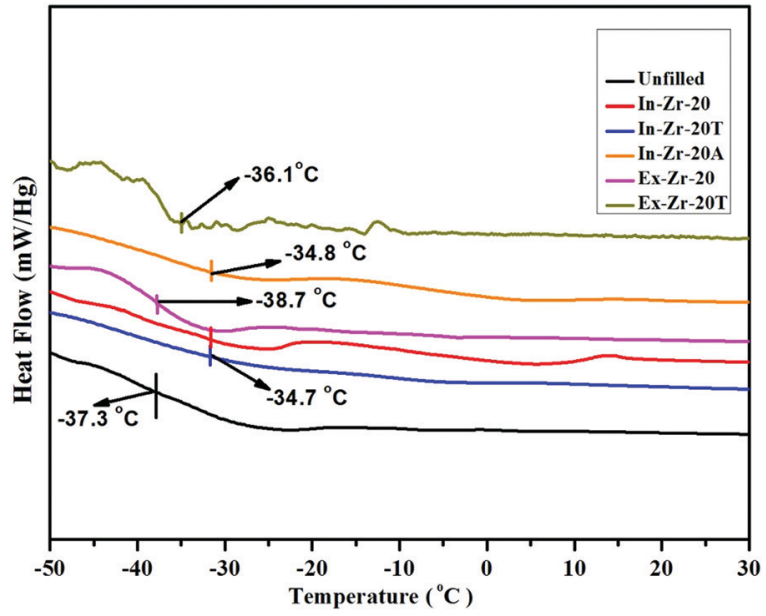

Fig. 2 DSC thermogram of CR gum and zirconia filled CR composites.

exhibit a lower value of $\Delta C_{\mathrm{p}}$ than the unfilled composite. To justify such decrease in $\Delta C_{\mathrm{p}}$, the fraction of the immobilized rubber layer $\left(\chi_{\mathrm{im}}\right)$ on the filler surface is calculated using. ${ }^{46}$ From Table 4 , it can be seen that the amount of immobilized rubber layer on the filler surface is $5 \%$ for the untreated zirconia filled composite (In-Zr-20) while it becomes about four times (23.19\%) and seven times $(37.50 \%)$ for TESPT and APTES treated zirconia filled composites, respectively. This clearly rationalises that although the filler content is the same in both the cases, the greater fraction of the immobilized rubber layer around the zirconia surface is responsible for such a decrease in the $\Delta C_{\mathrm{p}}$ value. $^{46,47}$

$$
\chi_{\mathrm{im}}=1-\frac{\Delta C_{\mathrm{p}}}{\Delta C_{\mathrm{p}} 0\left(1-W_{\text {filler }}\right)}
$$

where $\Delta C_{\mathrm{p}}^{\circ}$ and $\Delta C_{\mathrm{p}}$ are the specific heat capacity increase of neat and filled CR, respectively, and $W_{\text {filler }}$ is the weight fraction of zirconia.

\subsection{Morphology}

One of the objectives of the present study is to ensure a uniform dispersion of nano zirconia in the CR matrix and for this a solgel derived in situ incorporation technique has been adopted. SEM-EDX of $20 \mathrm{phr}$ zirconia filled composites is performed and the micrographs are presented in Fig. 3(a-d). SEM micrographs reveal the presence of large aggregates of zirconia particles of average particle size ranging between 130 and $140 \mathrm{~nm}$ in externally filled composites. On the other hand, a very uniform state of dispersion of zirconia, with significant reduction in size

Table 3 Thermogravimetric analysis, char yield and limiting oxygen index values (LOI) of unfilled and zirconia filled composites

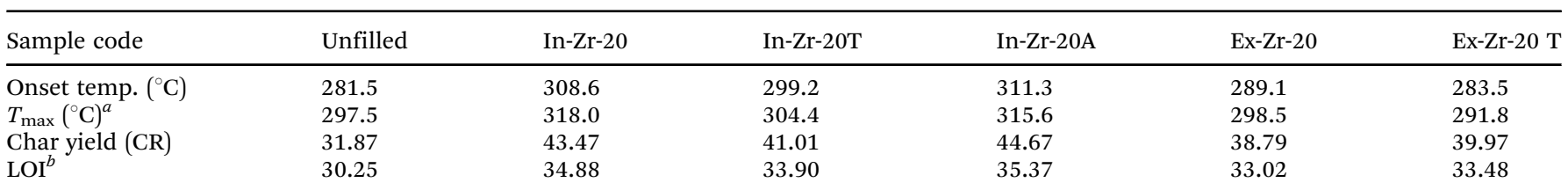

${ }^{a}$ Temperature at maximum weight loss ${ }^{*}$ Temp. range. $40-800{ }^{\circ} \mathrm{C} .{ }^{b}$ LOI-limiting oxygen index. 
Table 4 Glass transition temperature and heat capacity of selected composites

\begin{tabular}{llllll}
\hline Sample code & Unfilled & In-Zr-20 & In-Zr-20T & In-Zr-20A & Ex-Zr-20 \\
\hline$T_{\mathrm{g}}\left({ }^{\circ} \mathrm{C}\right)$ & -37.3 & -34.7 & -34.7 & -34.8 & -38.7 \\
$\Delta C_{\mathrm{p}}\left(10^{-3}\right)\left(\mathrm{J}\left(\mathrm{g} \mathrm{K}^{-1}\right)\right.$ & 0.964 & 0.761 & 0.617 & 0.502 & 0.561 \\
$\chi_{\mathrm{im}}$ & 0.0000 & 0.0527 & 0.2319 & 0.3750 & 0.3016
\end{tabular}

(a)

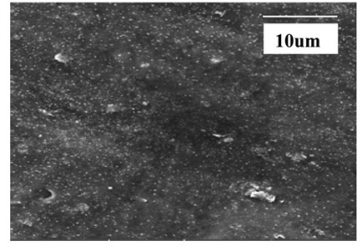

(c)

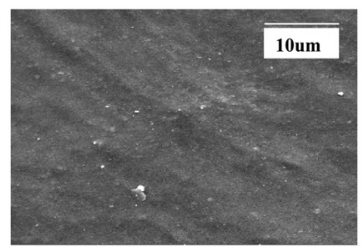

(b)

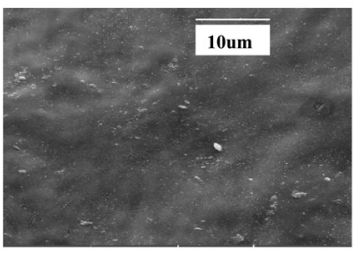

(d)

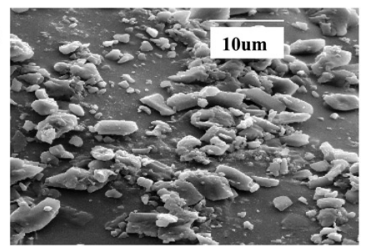

Fig. 3 Scanning electron microscopy (SEM) images of (a) In-Zr-20; (b) In$\mathrm{Zr}-20 \mathrm{~T}$; (c) In-Zr-20A and (d) Ex-Zr-20T.

(between 80 and $100 \mathrm{~nm}$ ), is observed in the case of $i n$ situ filled composites. Additionally, the use of a silane coupling agent (both for TESPT and APTES) has been found to further improve the state of dispersion. The surface of zirconia being polar, due to the presence of hydroxyl groups, initiates filler-filler interactions via hydrogen bonds. This acts as a barrier against uniform filler dispersion in the rubber matrix. The bifunctional silane coupling agents are proven to be very effective in tackling this issue. ${ }^{48,49}$ The present study clearly demonstrates the role of a silane coupling agent in reducing the filler-filler interaction and in enhancing the rubber-filler compatibility.

Energy dispersive spectra (EDX) are presented in Fig. 4. All the spectra show the peaks of $\mathrm{Zr}$ and $\mathrm{O}$ confirming the presence of $\mathrm{ZrO}_{2}$ particles in the composites. The quantitative data of the elements, distributed on the surface of composites, are given in Supplementary Table S1 $\left(\mathrm{ESI}^{1}\right)$. Weight $\%$ and atomic wt $\%$ are determined as average values of the investigated surface area.

\subsection{Mechanical characteristics}

Achieving adequate reinforcement in the composite by uniform dispersion of zirconia is the primary focus of this study. Therefore, an in-depth evaluation of the mechanical properties by stressstrain study has been undertaken. Analysis of the data in Table 5 and Fig. 5 clearly shows that moduli from $50 \%$ to $300 \%$ strain for all the in situ filled composites become much higher (three to five times) compared to those of unfilled gum. What's more, this becomes much more prominent for both the silane treated in situ zirconia filled composites. Tensile strength is also found to improve consistently along the same lines (three to four times higher). Such an outstanding improvement in stress-strain properties is primarily attributed to the controlled incorporation of rigid zirconia in the $\mathrm{CR}$ matrix under optimized reaction

conditions that ensures a very uniform dispersion of zirconia in the CR matrix. The use of a bifunctional silane coupling agent (both TESPT and APTES), in the reactive sol-gel system of zirconia incorporation, further intensifies the effect by bridging them via its two terminals. ${ }^{48}$ On the other side, moduli at low strain and tensile strength for externally zirconia filled composites are relatively inferior even at the same zirconia content. This clearly exposes the limitation of zirconia loading by physical mixing, compared to in situ loading, in bringing uniform filler dispersion and improved rubber-filler interaction in spite of using a silane coupling agent. ${ }^{50}$

The reciprocal relationship of crosslinking density and degree of swelling is established in Table 5 (details are given in the Experimental section). Crosslinking density increases with zirconia incorporation due to enhanced CR-zirconia interaction and the effect is the maximum for In-Zr-20T and In-Zr-20A. Variation of crosslinking density is reflected in elongation at the break value of the composites. Elongation at break becomes lower for in situ filled composites while the reverse trend is shown by externally filled composites. This is again a consequence of agglomeration and poor rubber filler interaction for the latter class of composites.

The degree of reinforcement in rubber composites not only depends on the amount of filler but on its size, shape, geometry, rubber-filler interaction and dispersion in the rubber matrix as well. ${ }^{51}$ In order to understand the reinforcing mechanism of the filled composites, experimentally derived relative moduli $\left(E_{\mathrm{c}} / E_{\mathrm{o}}\right)$ are compared with those calculated using the Guth-Gold equation (eqn (8)). It is evident that the experimental $E_{\mathrm{c}} / E_{\mathrm{o}}$ values are much higher than the theoretical values. This is a clear indication of strong rubber-filler interaction. To rationalise this observation, the shape factor (aspect ratio) is determined for each volume fraction of filler using the modified Guth-Gold equation ${ }^{52}$ (eqn (9)) (Table 6).

$$
\text { Guth-Gold equation: } E_{\mathrm{c}} / E_{\mathrm{o}}=1+2.5 \phi+14.1 \phi^{2}
$$

Modified Guth-Gold equation: $E_{\mathrm{c}} / E_{\mathrm{o}}=1+0.67 \phi f+1.62 f^{2} \phi^{2}$

where $E_{\mathrm{c}}$ and $E_{\mathrm{o}}$ are the Young's moduli of the filled andhfilled rubber composites, respectively, $\phi$ is the volume fraction of different in situ filled zirconia composites, and $f$ is the shape factor (aspect ratio) defined as the ratio of the length $(L)$ and width $(W)$ of the filler particle.

Aspect ratios of the fillers are found in the range 9-11 (Table 6). Therefore, it is very apparent that the shape and size of the filler can also be very crucial in governing the overall reinforcement of the composites. This observation is in good agreement with other studies on the effects of anisotropy and 
(a)

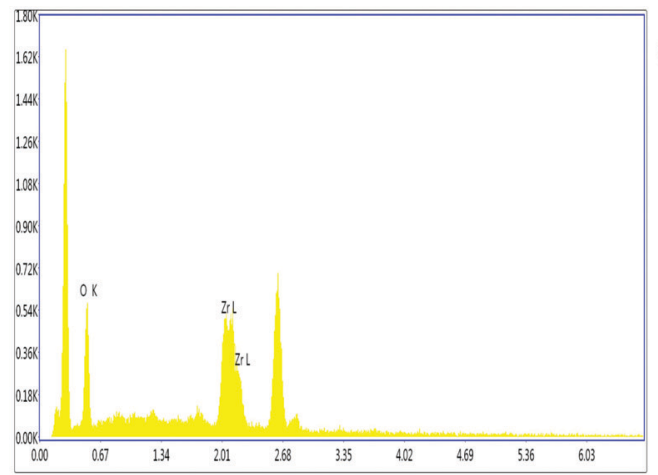

(c)
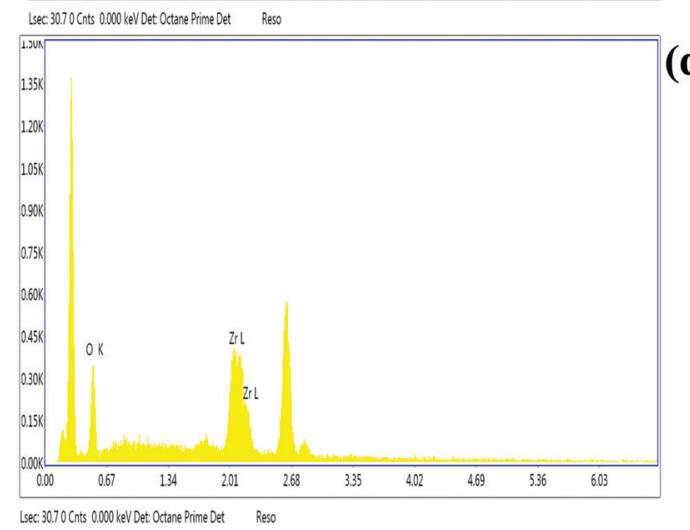

(b)

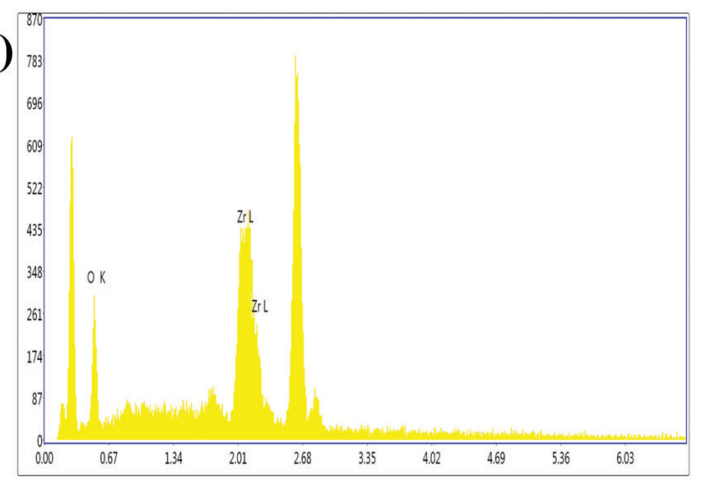

Leec 30.70 C nots 0.000 keV Det: Octane Prime Det Reso

(d)

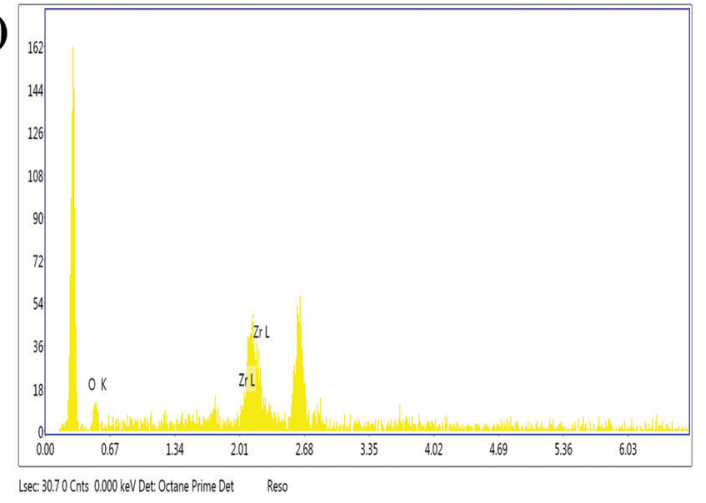

Fig. 4 EDX spectra of (a) In-Zr-20; (b) In-Zr-20T; (c) In-Zr-20A and (d) Ex-Zr-20T.

Table 5 Mechanical properties of unfilled and zirconia filled composites

\begin{tabular}{lllllll}
\hline Sample code & Unfilled & In-Zr-20 & In-Zr-20T & In-Zr-20A & Ex-Zr-20 & Ex-Zr-20T \\
\hline$\sigma_{50 \%}(\mathrm{MPa})$ & $0.57 \pm 0.143$ & $2.90 \pm 0.21$ & $3.26 \pm 0.310$ & $3.23 \pm 0.08$ & $0.037 \pm 0.21$ & $0.28 \pm 0.06$ \\
$\sigma_{100 \%}(\mathrm{MPa})$ & $1.03 \pm 0.17$ & $4.62 \pm 0.21$ & $5.57 \pm 0.47$ & $5.37 \pm 0.12$ & $0.98 \pm 0.35$ & $0.65 \pm 0.05$ \\
$\sigma_{200 \%}(\mathrm{MPa})$ & $1.81 \pm 0.40$ & $7.10 \pm 0.40$ & $9.74 \pm 0.99$ & $9.29 \pm 0.18$ & $1.39 \pm 0.15$ & $1.67 \pm 0.11$ \\
$\sigma_{300 \%}(\mathrm{MPa})$ & $2.40 \pm 0.15$ & $9.56 \pm 0.23$ & $5.21 \pm 2.13$ & $8.92 \pm 0.30$ & $2.16 \pm 0.27$ & $2.39 \pm 0.25$ \\
Tensile strength (MPa) & $3.31 \pm 0.70$ & $10.39 \pm 0.47$ & $11.10 \pm 0.35$ & $11.60 \pm 0.10$ & $9.98 \pm 0.20$ & $10.50 \pm 0.21$ \\
Elongation at break (\%) & $338.67 \pm 97.72$ & $325.67 \pm 34.38$ & $235.00 \pm 19.67$ & $257.33 \pm 6.43$ & $649.00 \pm 35.12$ & $676.00 \pm 18.38$ \\
Degree of swelling & 273.43 & 130.86 & 122.97 & 116.55 & 220.99 & 226.89 \\
Cross-linking density $\left(\nu \times 10^{-4}\right)$ & 3.13 & 5.07 & 6.45 & 6.53 & 2.58 & 1.93 \\
Reinforcing efficiency (RE) & - & 0.215 & 0.272 & 0.260 & 0.003 & 0.038 \\
\hline
\end{tabular}

shape factors with different kinds of anisotropic fillers in rubber composites reported in the literature. ${ }^{52-55}$

To have a further insight into the quantitative aspect of the reinforcement effect brought by zirconia, the reinforcing efficiency (RE) values are derived from eqn (10) (Table 5). ${ }^{56}$ Superior reinforcing efficiency of in situ zirconia is exhibited, in particular, for silane treated in situ zirconia, when compared with that of externally added zirconia. We were curious to compare the reinforcement of CR by zirconia found in the present work with those of some reported studies. The RE values of $20 \mathrm{phr}$ of aluminum trihydrate ${ }^{41}$ and precipitated silica $^{57}$ for CR are reported as 0.156 and 0.021 , respectively, in separate studies. In another work, RE of a different silane modified silica ${ }^{48}$ (40 phr) for CR composites is reported in the range of 0.007 to 0.038 . Das et al. ${ }^{36}$ reported CR based nanocomposites where varieties of modified nanoclays (5 phr)

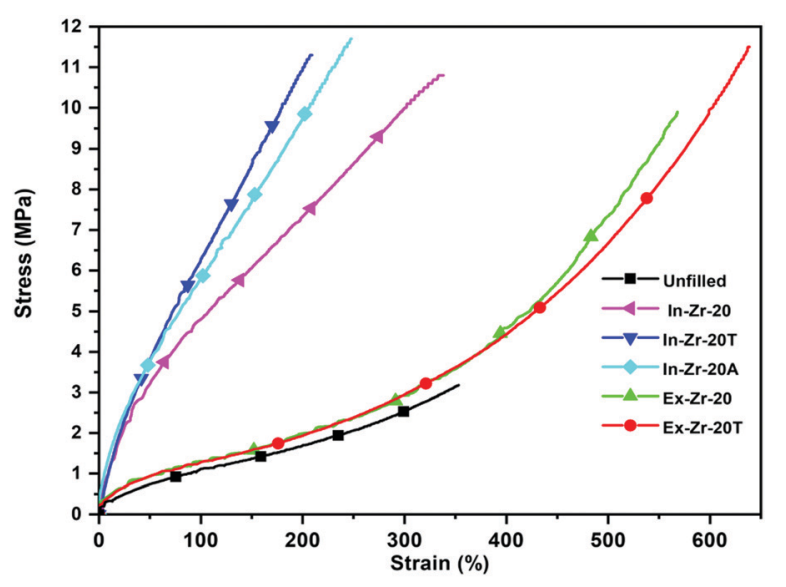

Fig. 5 Stress-strain curve of unfilled and zirconia filled CR composites. 
Table 6 Aspect ratio calculated using the modified Guth-Gold equation

\begin{tabular}{llllr}
\hline Sample code & Volume fraction $(\phi)$ & Relative modulus $\left(E_{\mathrm{c}} / E_{\mathrm{o}}\right)($ experimental $)$ & Relative modulus $\left(E_{\mathrm{c}} / E_{\mathrm{o}}\right)($ theoretical $)$ & Aspect ratio $(f)$ \\
\hline Unfilled & 0 & 1 & 1 & - \\
In-Zr-20 & 0.1580 & 5.2296 & 1.3950 & 9.0013 \\
In-Zr-20T & 0.1412 & 5.8596 & 1.3530 & 10.8887 \\
In-Zr020A & 0.1719 & 5.8000 & 1.4297 & 8.8825
\end{tabular}

were employed and the highest RE value reported for CR-OMMT (organically modified montmorillonite) was 0.241 . What's more, in those reports, the ratio of the tensile strength of filled composite to that of unfilled composites ranges between 0.9 and 1.7. Notably, this is found above 3.0 in the present case. This clearly establishes the superior reinforcement of CR composites brought by in situ zirconia in the present study.

$$
\mathrm{RE}=\frac{\sigma 100 \% \text { filled }-\sigma 100 \% \text { filled }}{\mathrm{wt} \% \text { filler }}
$$

\subsection{Dynamic mechanical analysis (DMA)}

Dynamic mechanical analysis of the composites has been performed to assess their suitability for dynamic application. In Fig. 6(a), the temperature-dependent storage modulus $(E)$ curve reveals a higher storage modulus value of all the zirconia filled CR composites relative to the unfilled gum in the rubbery region. The increase is significantly more for in situ zirconia than for externally filled zirconia. Furthermore, a plot of temperature versus loss tangent ( $\tan \delta$ ) (Fig. 6(b)) shows a steady decrease in the peak height of $\tan \delta$ for all the in situ filled zirconia composites relative to the unfilled one. Such an increase in the storage modulus value in the rubbery region and reduction in peak height of $\tan \delta$ for in situ filled composites are a clear indication of the prominent reinforcement effect and strong-rubber filler interaction brought by in situ incorporation of zirconia in the CR matrix. At the same time, the poor reinforcing effect of externally filled CR-zirconia composites, found in the DMA study, is consistent with other observations discussed in the previous section. (a)

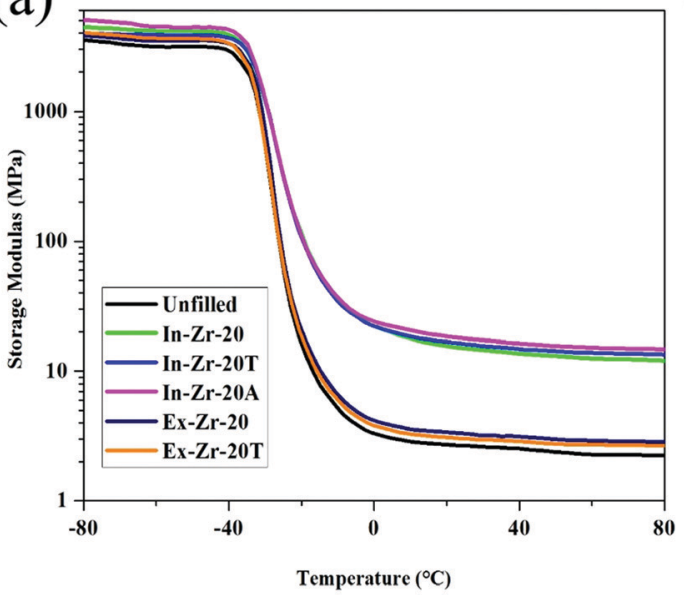

(c)

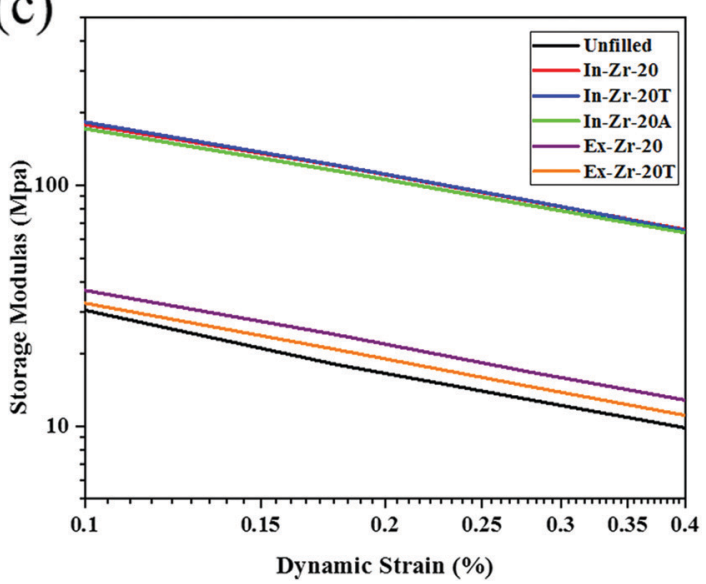

(b)

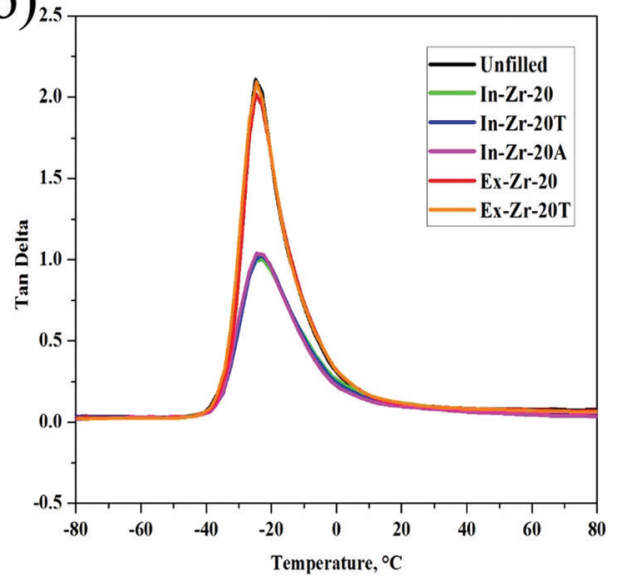



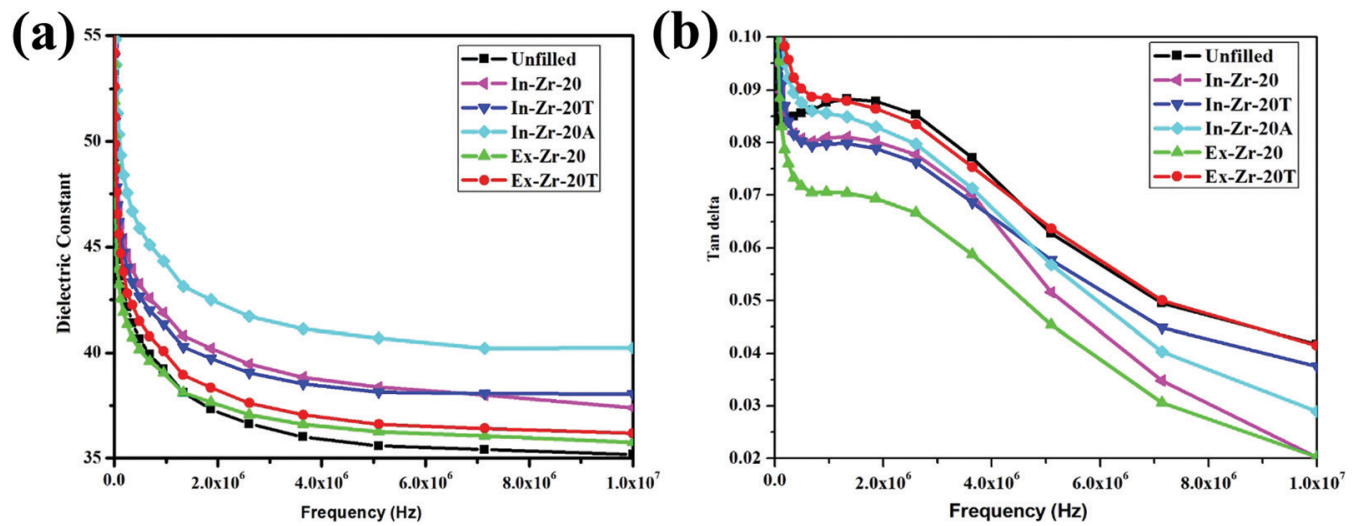

Fig. 7 Dielectric properties of unfilled and filled composites. (a) Dielectric constant as a function of frequency and (b) tan delta as a function of frequency.

Fig. 6(c) presents the plot of storage modulus as a function of dynamic strain to consider the Payne effect. In general for unfilled gums, dynamic modulus does not depend on the dynamic strain. But in our case, the gum also shows the Payne effect which may be due to the disentanglement of chains caused upon the application of strain. ${ }^{41}$ With an increase in the strain, the cyclic breakdown as well as reformation of filler network occurs. However, at a high strain, the destruction rate is higher than that of re-formation which results in a decrease in storage modulus. This is why at a lower strain, for all the in situ zirconia filled composites, the filler-filler interaction is found to be stronger and dominating. But at a higher strain, the filler-filler interaction is suppressed and as a result, a regular decrease in the modulus value is observed. It is important to note here that the externally filled composites, even with the same filler content, do not show a considerable Payne effect. In this case, stronger aggregation of zirconia does not allow it to contribute to the modulus value at a lower strain.

\subsection{Dielectric study}

Chloroprene rubber (CR) is known to demonstrate good electric properties because of the presence of chloro groups adjacent to carbon-carbon double bonds. ${ }^{58}$ The frequency dependence of the dielectric constant and dielectric loss tangent $(\tan \delta)$ of all the zirconia filled composites, at room temperature is presented in Fig. 7. A high dielectric constant value of the unfilled compound, at a low frequency region, is evident in the figure that is caused by an induced polarisation by polar CR. ${ }^{59}$ Notably, at the same frequency region, the dielectric constant of all the zirconia filled composites becomes higher and to a greater extent in the case of in situ filled zirconia composites. This can be justified in terms of a very good state of dispersion of in situ zirconia particles in the CR matrix that leads to more interfacial polarization. ${ }^{60}$ However, at the higher frequency side, the dielectric constant of all the composites including that of the unfilled one is decreased. This happens due to the interfacial polarization effect in which dipoles practically have no time to orient themselves in the speed of the field at high frequency. In Fig. 7(b), it can be seen that initially there is a decrease in the tan delta value with an increase in frequency. Next, all the composites pass through a maximum peak as a consequence of some dielectric relaxation processes. Different types of interactions between CR and zirconia are primarily responsible for such a dielectric relaxation process. ${ }^{41}$ Alpha relaxation is generally observed in the lower frequency region which is due to the segmental motion of polymer backbone chains that leads to inter chain interactions between polymer segments while beta relaxation is observed in the middle frequency region which is due to the relaxation of side chain groups involved in interaction with filler particles. ${ }^{61}$ What is very encouraging to note here is that the $\tan \delta$ values of the composites are less than 0.10 over the whole frequency range which makes the composites suitable for electronic application. ${ }^{3}$

\subsection{Evaluating the practical applicability of the synthesised composites through a series of testing}

All the synthesised composites have been rigorously subjected to a series of testing to check their material performance and their suitability to fit for practical applications. ASTM standard

Table 7 Oil and abrasion resistance of unfilled and CR-zirconia filled composites

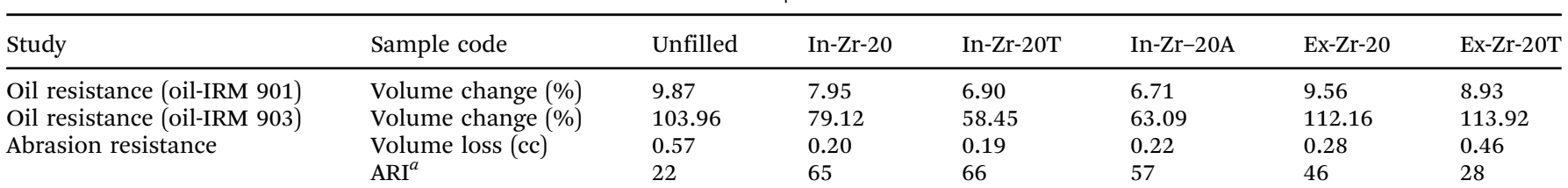

${ }^{a}$ ARI: abrasion resistance index. 
(Experimental section) was followed in each case and the results are discussed below.

4.8.1 Oil resistance. CR being polar in nature exhibits excellent oil resistance property towards hydrocarbon oil and is used where resistance towards solvent attack is required. Oil-resistant polyrubber composites are of great significance for the automobile industry, because a range of replacement components may come into contact with oils and greases. The oil resistance property of the CR composites is studied here in terms of volume change with two standard oils viz. IRM 901 and IRM 903 as per ASTM D471. Volume change, a measure of oil resistance, is found to decrease significantly upon the incorporation of in situ zirconia (Table 7). Among all the composites, maximum oil resistance is shown by in situ zirconia filled silane treated composites (In-Zr-20T and In-Zr-20A). Strong rubber filler interaction and increase in cross-linking density prevent the oil molecules from permeating into the vulcanized rubbers which in turn decreases the rate of oil transport in the rubber matrix. ${ }^{62}$ Additionally, incorporation of zirconia could also contribute in this regard by enhancing the polar character of the composite. ${ }^{63}$ In contrast, the reverse trend is observed for externally filled composites which might be due to clustering of loosely bound nanoparticles and a decrease in the crosslinking density of the composites $^{64}$ (Table 7).

4.8.2 Abrasion resistance. Under working conditions, the rubber materials could meet mechanical failure under prolonged exposure to various stresses through rubbing, chunking, tearing and abrading. This could also eventually terminate the usable life of rubber composites. Different fillers are added to the rubber matrix to address this issue. ${ }^{65}$ In this study, abrasion resistance of all the composites has been assessed through volume loss and the abrasion resistance index (ARI). The data in Table 7 clearly show considerable reduction in volume change and the corresponding raise in ARI for all the in situ zirconia filled composites relative to that of the unfilled compound. Therefore, in situ zirconia certainly improves the abrasion resistance property of the composites appreciably relative to externally filled zirconia.

4.8.3 Aging resistance. Chloroprene rubber (CR) is appreciated for its aging resistance property contributed by the electronegative chlorine atom which deactivates the double bond of CR. Aging resistance of the synthesized composites is studied by comparing the mechanical properties of the composites before and after thermal ageing at $100{ }^{\circ} \mathrm{C}$ for $72 \mathrm{~h}$ (Table 8).

During thermal aging, scission of the polymeric backbone, crosslink formation and cross link breakage can occur that directly affect the mechanical properties of the elastomers. ${ }^{66,67}$ Here, modulus values of the composites are found to increase after aging and in a greater extent for in situ filled composites (Fig. S1(a), ESI †). This happens due to post curing when the composites are exposed to high temperature. Post curing could occur by the chemical reactions between the silanol group present on the zirconia surface and the chlorine atom of CR forming additional cross links. The tensile strength was 
reduced for all the composites (except In-Zr-20T) after aging. ${ }^{68}$ However, it is important to note here that the retention of tensile strength for in situ filled composites is quite significant as compared to other composites (Fig. S1(b), ESI $\dagger$ ).

\section{Conclusions}

The effect of zirconia, as a non-black filler, on the composite properties of chloroprene rubber has been investigated from different viewpoints. The outstanding reinforcement offered by zirconia is primarily contributed by a very uniform state of dispersion of zirconia in the CR matrix. This is brought by solgel derived in situ incorporation of zirconia into the rubber matrix under optimized reaction conditions. This effect is further intensified in the presence of two chosen organosilanes. The thermal stability of the composites is found to improve significantly upon zirconia incorporation. To examine the feasibility of the composites in withstanding the practical working conditions, a series of standard testing methods are followed. The analysis of the data reveals very good response of the composites towards resistance to oil, abrasion and aging. Furthermore, in situ zirconia is found to enrich the dielectric properties of the composites as well. The unique combination of dielectric and mechanical properties in the zirconia filled CR composites seems very promising for the development of highfrequency electronic equipment.

\section{Conflicts of interest}

There are no conflicts to declare.

\section{Acknowledgements}

This work was financially supported by IRMRA, Thane (Project code: IRMRA/R\&D/16-17/EXT-VNIT/03). Characterization support received from DST-FIST sponsored research facilities at the Chemistry Department, VNIT, Nagpur, is acknowledged. SCA acknowledges VNIT for fellowship assistance.

\section{References}

1 K. Roy, S. C. Debnath and P. Potiyaraj, A critical review on the utilization of various reinforcement modifiers in filled rubber composites, J. Elastomers Plast., 2020, 52(2), 167-193.

2 W. Rathnayake, H. Ismail, A. Baharin, I. Bandara and S. Rajapakse, Enhancement of the antibacterial activity of natural rubber latex foam by the incorporation of zinc oxide nanoparticles, J. Appl. Polym. Sci., 2014, 131(1), 39601.

3 M. Ruan, D. Yang, W. Guo, L. Zhang, S. Li, Y. Shang, Y. Wu, M. Zhang and H. Wang, Improved dielectric properties, mechanical properties, and thermal conductivity properties of polymer composites via controlling interfacial compatibility with bio-inspired method, Appl. Surf. Sci., 2018, 439, 186-195.
4 C. Das, N. D. Bansod, B. P. Kapgate, K. Rajkumar and A. Das, Incorporation of titania nanoparticles in elastomer matrix to develop highly reinforced multifunctional solution styrene butadiene rubber composites, Polymer, 2019, 162, 1-10.

5 H. Wang, P. Xu, W. Zhong, L. Shen and Q. Du, Transparent poly (methyl methacrylate)/silica/zirconia nanocomposites with excellent thermal stabilities, Polym. Degrad. Stab., 2005, 87(2), 319-327.

6 Y. Fan, G. D. Fowler and M. Zhao, The past, present and future of carbon black as a rubber reinforcing filler-A review, J. Cleaner Prod., 2020, 247, 119115.

7 S. Kang, S. I. Hong, C. R. Choe, M. Park, S. Rim and J. Kim, Preparation and characterization of epoxy composites filled with functionalized nanosilica particles obtained via sol-gel process, Polymer, 2001, 42(3), 879-887.

8 A. Bandyopadhyay, M. De Sarkar and A. Bhowmick, Epoxidised natural rubber/silica hybrid nanocomposites by solgel technique: Effect of reactants on the structure and the properties, J. Mater. Sci., 2005, 40(1), 53-62.

9 Y. Ikeda, S. Poompradub, Y. Morita and S. Kohjiya, Preparation of high performance nanocomposite elastomer: Effect of reaction conditions on in situ silica generation of high content in natural rubber, J. Sol-Gel Sci. Technol., 2008, 45(3), 299-306.

10 M. Messori, F. Bignotti, R. De Santis and R. Taurino, Modification of isoprene rubber by in situ silica generation, Polym. Int., 2009, 58(8), 880-887.

11 B. P. Kapgate, C. Das, D. Basu, A. Das, G. Heinrich and U. Reuter, Effect of silane integrated sol-gel derived in situ silica on the properties of nitrile rubber, J. Appl. Polym. Sci., 2014, 131, 15.

12 N. D. Bansod and C. Das, Studies on mechanical, rheological, thermal and morphological properties of in situ silicafilled butadiene rubber composites, Plast., Rubber Compos., 2018, 47(8), 345-351.

13 K. Stockelhuber, A. Svistkov, A. Pelevin and G. Heinrich, Impact of filler surface modification on large scale mechanics of styrene butadiene/silica rubber composites, Macromolecules, 2011, 44(11), 4366-4381.

14 A. Bouty, L. Petitjean, C. Degrandcourt, J. Gummel, P. Kwaśniewski, F. Meneau, F. o. Boué, M. Couty and J. Jestin, Nanofiller structure and reinforcement in model silica/rubber composites: A quantitative correlation driven by interfacial agents, Macromolecules, 2014, 47(15), 5365-5378.

15 D. Yang, S. Huang, Y. Wu, M. Ruan, S. Li, Y. Shang, X. Cui, Y. Wang and W. Guo, Correction: Enhanced actuated strain of titanium dioxide/nitrile-butadiene rubber composite by the biomimetic method, RSC Adv, 2015, 5(86), 70500.

16 M. Alexandru, M. Cazacu, A. Nistor, V. E. Musteata, I. Stoica, C. Grigoras and B. C. Simionescu, Polydimethylsiloxane/ silica/titania composites prepared by solvent-free sol-gel technique, J. Sol-Gel Sci. Technol., 2010, 56(3), 310-319.

17 C. Das, N. D. Bansod, B. P. Kapgate, U. Reuter, G. Heinrich and A. Das, Development of highly reinforced acrylonitrile 
butadiene rubber composites via controlled loading of solgel titania, Polymer, 2017, 109, 25-37.

18 X. Kong, D. Yang, Y. Ni, J. Hao, W. Guo and L. Zhang, Enhanced actuation strains of rubber composites by combined covalent and noncovalent modification of TiO2 nanoparticles, Ind. Eng. Chem. Res., 2019, 58(43), 19890-19898.

19 G. Garnweitner, Zirconia nanomaterials: Synthesis and biomedical application, Nanotechnologies for the Life Sciences, 2009, 10, 9783527610419.

20 Y. Hu, G. Gu, S. Zhou and L. Wu, Preparation and properties of transparent PMMA/ZrO2 nanocomposites using 2hydroxyethyl methacrylate as a coupling agent, Polymer, 2011, 52(1), 122-129.

21 X. Ma, C. Peng, D. Zhou, Z. Wu, S. Li, J. Wang and N. Sun, Synthesis and mechanical properties of the epoxy resin composites filled with sol-gel derived $\mathrm{ZrO} 2$ nanoparticles, J. Sol-Gel Sci. Technol., 2018, 88(2), 442-453.

22 S. Anandhi, M. L. Edward and V. Jaisankar, Synthesis, characterization and antimicrobial activity of polyindole/ ZrO2 nanocomposites, Mater. Today: Proc., 2021, 40, S93-S101.

23 M. I. Sarwar, S. Zulfiqar and Z. Ahmad, Properties of polyamide-zirconia nanocomposites prepared from sol-gel technique, Polym. Compos., 2009, 30(1), 95-100.

24 R. Selyanchyn and S. Fujikawa, Molecular hybridization of polydimethylsiloxane with zirconia for highly gas permeable membranes, ACS Appl. Polym. Mater., 2019, 1(5), 1165-1174.

25 M. V. Carević, N. Abazović, M. Mitrić, G. irić-Marjanović, M. Mojović, S. P. Ahrenkiel and M. Čomor, Properties of zirconia/polyaniline hybrid nanocomposites and their application as photocatalysts for degradation of model pollutants, Mater. Chem. Phys., 2018, 205, 130-137.

26 W. A. K. Mahmood, M. M. R. Khan and M. H. Azarian, Solgel synthesis and morphology, thermal and optical properties of epoxidized natural rubber/zirconia hybrid films, J. Non-Cryst. Solids, 2013, 378, 152-157.

27 M. H. Azarian and W. A. K. Mahmood, In situ sol-gel synthesis of zirconia networks in flexible and conductive composite films, J. Appl. Polym. Sci., 2020, 137(46), 49506.

28 D. Yang, W. Zhang, B. Jiang and Y. Guo, Silicone rubber ablative composites improved with zirconium carbide or zirconia, Composites, Part A, 2013, 44, 70-77.

29 J. Wen and J. E. Mark, Synthesis, structure, and properties of poly (dimethylsiloxane) networks reinforced by in situprecipitated silica-titania, silica-zirconia, and silica-alumina mixed oxides, J. Appl. Polym. Sci., 1995, 58(7), 1135-1145.

30 S. Murugesan, J. E. Mark and G. Beaucage, Structure-Property Relationships for Poly (dimethylsiloxane) Networks In Situ Filled Using Titanium 2-Ethylhexoxide and Zirconium nButoxide, ACS Publications, 2001.

31 S. Utrera-Barrios, R. Perera, N. León, M. H. Santana and N. Martínez, Reinforcement of natural rubber using a novel combination of conventional and in situ generated fillers, Composites, Part C, 2021, 5, 100133.
32 D. Amrishraj and T. Senthilvelan, Acrylonitrile butadiene styrene composites reinforced with nanozirconia and PTFE: Mechanical and thermal behavior, Polym. Compos., 2018, 39(S3), E1520-E1530.

33 Y. A. Treger, K. Morozov, G. Dasaeva and A. Frolkova, Chloroprene rubber: Application and production, Fine Chem. Technol., 2018, 13(4), 26-38.

34 M. Maya, S. C. George, T. Jose, L. Kailas and S. Thomas, Development of a flexible and conductive elastomeric composite based on chloroprene rubber, Polym. Test., 2018, 65, 256-263.

35 B. P. Kapgate, C. Das, A. Das, D. Basu, S. Wiessner, U. Reuter and G. Heinrich, Reinforced chloroprene rubber by in situ generated silica particles: Evidence of bound rubber on the silica surface, J. Appl. Polym. Sci., 2016, 133, 30.

36 A. Das, F. R. Costa, U. Wagenknecht and G. Heinrich, Nanocomposites based on chloroprene rubber: Effect of chemical nature and organic modification of nanoclay on the vulcanizate properties, Eur. Polym. J., 2008, 44(11), 3456-3465.

37 L. Kong, Y. Zhu, G. Huang and J. Wu, Carbon nanodots as dual role of crosslinking and reinforcing chloroprene rubber, Compos. Commun., 2020, 22, 100441.

38 S. C. Ambilkar, N. D. Bansod, B. P. Kapgate, A. Das, P. Formanek, K. Rajkumar and C. Das, In situ zirconia: A superior reinforcing filler for high-performance nitrile rubber composites, ACS Omega, 2020, 5(14), 7751-7761.

39 D. W. Van Krevelen and P. Hoftyzer, Properties of polymers: their estimation and correlation with chemical structure/by DW van Krevelen, with the collaboration of PJ Hoftyzer.

40 L. H. Sperling, Introduction to physical polymer science, John Wiley \& Sons, 2005.

41 D. Vijayan, A. Mathiazhagan and R. Joseph, Aluminium trihydroxide: novel reinforcing filler in polychloroprene rubber, Polymer, 2017, 132, 143-156.

42 A. Karaulov, T. Piskun and N. Kvasman, Physical and mechanical properties of zirconium dioxide refractories and their resistance to attack by molten metals, Refractories, 1993, 34(7), 367-375.

43 S. Mallakpour and F. Zeraatpisheh, Novel flame retardant zirconia-reinforced nanocomposites containing chlorinated poly(amide-imide): Synthesis and morphology probe, J. Exp. Nanosci., 2014, 9(10), 1035-1050.

44 A. Martos, M. Soto, H. Schäfer, K. Koschek, J. Marquet and R. M. Sebastián, Highly crosslinked polybenzoxazines from monobenzoxazines: The effect of meta-substitution in the phenol ring, Polymers, 2020, $12(2), 254$.

45 J.-J. Li, J. Sun, Y.-X. Xie, C. Zhao, H.-X. Ma and C.-M. Liu, A novel star-shaped, cardanol-based bio-prepolymer: Synthesis, UV curing characteristics and properties of cured films, Polym. Degrad. Stab., 2018, 158, 124-135.

46 D. Fragiadakis, L. Bokobza and P. Pissis, Dynamics near the filler surface in natural rubber-silica nanocomposites, Polymer, 2011, 52(14), 3175-3182.

47 A. Sargsyan, A. Tonoyan, S. Davtyan and C. Schick, The amount of immobilized polymer in PMMA SiO2 
nanocomposites determined from calorimetric data, Eur. Polym. J., 2007, 43(8), 3113-3127.

48 C. Siriwong, P. Sae-Oui and C. Sirisinha, Comparison of coupling effectiveness among amino-, chloro-, and mercapto silanes in chloroprene rubber, Polym. Test., 2014, 38, 64-72.

49 U. Goerl, A. Hunsche, A. Mueller and H. Koban, Investigations into the silica/silane reaction system, Rubber Chem. Technol, 1997, 70(4), 608-623.

50 L. Strohmeier, B. Schrittesser and S. Schlögl, Approaches toward in situ reinforcement of organic rubbers: Strategy and recent progress, Polym. Rev., 2021, 1-32.

51 B. Chaichua, P. Prasassarakich and S. Poompradub, In situ silica reinforcement of natural rubber by sol-gel process via rubber solution, J. Sol-Gel Sci. Technol., 2009, 52(2), 219-227.

52 S. Rooj, A. Das, K. W. Stöckelhuber, D.-Y. Wang, V. Galiatsatos and G. Heinrich, Understanding the reinforcing behavior of expanded clay particles in natural rubber compounds, Soft Matter, 2013, 9(14), 3798-3808.

53 S. Peddini, C. Bosnyak, N. Henderson, C. Ellison and D. Paul, Nanocomposites from styrene-butadiene rubber (SBR) and multiwall carbon nanotubes (MWCNT) part 1: Morphology and rheology, Polymer, 2014, 55(1), 258-270.

54 S. Hait, D. De, A. K. Ghosh, M. Al Aiti, P. Ghosh, J. Chanda, R. Mukhopadhyay, S. Dasgupta, S. Wießner and G. Heinrich, Treasuring waste lignin as superior reinforcing filler in high cis-polybutadiene rubber: A direct comparative study with standard reinforcing silica and carbon black, J. Cleaner Prod, 2021, 299, 126841.

55 N. D. Bansod, B. P. Kapgate, C. Das, A. Das, D. Basu and S. C. Debnath, Compatibilization of natural rubber/nitrile rubber blends by sol-gel nano-silica generated by in situ method, J. Sol-Gel Sci. Technol., 2016, 80(2), 548-559.

56 A. Das, R. Jurk, K. Werner Stöckelhuber and G. Heinrich, Silica-ethylene propylene diene monomer rubber networking by in situ sol-gel method, J. Macromol. Sci., Part A: Pure Appl. Chem., 2007, 45(1), 101-106.

57 P. Sae-oui, C. Sirisinha, U. Thepsuwan and K. Hatthapanit, Dependence of mechanical and aging properties of chloroprene rubber on silica and ethylene thiourea loadings, Eur. Polym. J., 2007, 43(1), 185-193.

58 B. P. Kapgate and C. Das, Electronic Applications of Chloroprene Rubber and Its Composites, in Flexible and Stretchable Electronic Composites, Springer, 2016, pp. 279-304.
59 A. Das, A. Ghosh and D. Basu, Evaluation of physical and electrical properties of chloroprene rubber and natural rubber blends. KGK, Kautschuk, Gummi, Kunststoffe, 2005, 58(5), 230-237.

60 K. Subramaniam, A. Das, D. Steinhauser, M. Klüppel and G. Heinrich, Effect of ionic liquid on dielectric, mechanical and dynamic mechanical properties of multi-walled carbon nanotubes/polychloroprene rubber composites, Eur. Polym. J., 2011, 47(12), 2234-2243.

61 J. K. Jung, Y. I. Moon, G. H. Kim and N. H. Tak, Characterization of dielectric relaxation process by impedance spectroscopy for polymers: Nitrile butadiene rubber and ethylene propylene diene monomer, J. Spectrosc., 2020, 8815492.

62 V. Jasna, T. Anilkumar, A. A. Naik and M. Ramesan, Chlorinated styrene butadiene rubber/zinc sulfide: Novel nanocomposites with unique properties-structural, flame retardant, transport and dielectric properties, J. Polym. Res., 2018, 25(6), 1-14.

63 Y. Meng, J. Chu, C. Liu, Z. Wei and L. Zhang, Oil resistance and mechanical properties of polysiloxane nanocomposites prepared by in situ reaction of reactive polar monomers, J. Appl. Polym. Sci., 2014, 131(21), 40983.

64 M. T. Ramesan, Effect of fly ash on thermal stability, flammability, oil resistance and transport properties of chlorinated styrene butadiene rubber composites, J. Elastomers Plast., 2014, 46(4), 303-324.

65 U. Thepsuwan, P. Sae-oui, C. Sirisinha and P. Thaptong, Influence of halloysite nanotube on properties of tire tread compounds filled with silica and carbon black hybrid filler, J. Appl. Polym. Sci., 2019, 136(4), 46987.

66 F.-Z. Li, M.-R. Gao, B. Guo and N. Bolf, Investigation of ageing behaviour of nitrile-butadiene rubber with added graphene in an accelerated thermal ageing environment, Kemija u industriji, 2018, 67(1-2), 29-37.

67 A. Mostafa, A. Abouel-Kasem, M. Bayoumi and M. El-Sebaie, The influence of CB loading on thermal aging resistance of SBR and NBR rubber compounds under different aging temperature, Mater. Des., 2009, 30(3), 791-795.

68 J. Diez, R. Bellas, J. López, G. Santoro, C. Marco and G. Ellis, Study of the crosslink density, dynamo-mechanical behaviour and microstructure of hot and cold SBR vulcanizates, J. Polym. Res., 2010, 17(1), 99-107. 